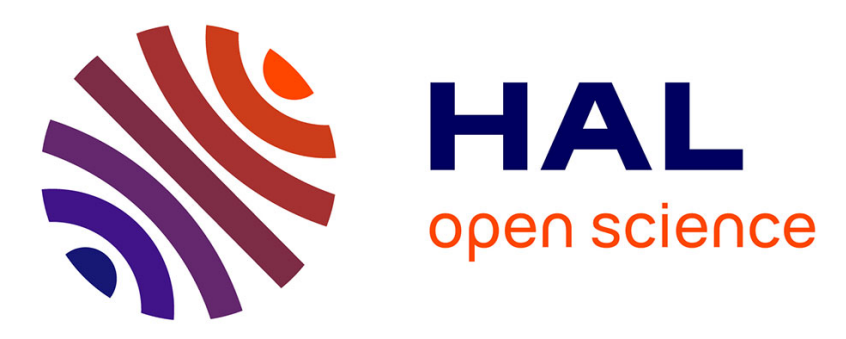

\title{
The effects of ambient temperature on the compaction of pharmaceutical powders
}

Abderrahim Michrafy, S Haas, Moulay S. Kadiri, K Sommer, John A. Dodds

\section{To cite this version:}

Abderrahim Michrafy, S Haas, Moulay S. Kadiri, K Sommer, John A. Dodds. The effects of ambient temperature on the compaction of pharmaceutical powders. Proceedings of the Institution of Mechanical Engineers, Part E: Journal of Process Mechanical Engineering, 2006, 220 (E1), pp.1-6. 10.1243/095440805X73636 . hal-01680767

\section{HAL Id: hal-01680767 https://hal.science/hal-01680767}

Submitted on 7 Nov 2019

HAL is a multi-disciplinary open access archive for the deposit and dissemination of scientific research documents, whether they are published or not. The documents may come from teaching and research institutions in France or abroad, or from public or private research centers.
L'archive ouverte pluridisciplinaire HAL, est destinée au dépôt et à la diffusion de documents scientifiques de niveau recherche, publiés ou non, émanant des établissements d'enseignement et de recherche français ou étrangers, des laboratoires publics ou privés. 


\title{
The effects of ambient temperature on the compaction of pharmaceutical powders
}

\author{
A Michrafy $^{1 *}$, S Haas ${ }^{2}$, M S Kadiri ${ }^{1}$, K Sommer $^{2}$, and J A Dodds ${ }^{1}$ \\ ${ }^{1}$ Chemical Engineering Laboratory for Particulate Solids, UMR 2392, Ecole des Mines d'Albi, Campus Jarlard, \\ Albi, France \\ ${ }^{2}$ TU München/Weihenstephan, Lehrstuhl für Maschinen- und Apparatekunde, Am Forum 2, Freising, Germany
}

\begin{abstract}
This article presents an experimental study of the effects of raised ambient temperature in dies and punches on the compaction of pharmaceutical powders. The experiments use an instrumented hydraulic press having a temperature-controlled enclosure allowing the ambient temperature of die and punch to be varied from 20 to $57^{\circ} \mathrm{C}$. A pharmaceutical powder was compacted at temperatures in this range and mechanical parameters, such as stress transfer ratio, stress transmission ratio, and die-wall friction, were analysed to examine the effects of heat transfer between tools and powder. In particular, it is shown that increasing the environmental temperature of die and punch increases the transfer ratio and the die-wall friction. The radial pressure is also slightly increased at the first stages of the compaction. However, the stress transmission is reduced by increasing the temperature. This may indicate an increase of shear stress. It is also observed that the particles undergoing compaction are 'softened' by increase of the temperature. This softening is certainly due to rise in temperature of the powder generated by the compaction and by the heat flux transfer between the die and the tablet. It is suggested that these effects could be important in industrial tablet production installations without air conditioning and thus subject to variations in ambient temperature.
\end{abstract}

Keywords: compaction, environmental temperature, mechanical behaviour, pharmaceutical powder

\section{INTRODUCTION}

Powder compaction is an important particle size enlargement process widely used in the pharmaceutical industry for producing tablets. The user properties of powder compacts depend on the process parameters. The distribution of relative density in the compacts depends on the non-uniform transmission of uniaxial compaction pressure with respect to internal friction and die-wall friction. In addition, industrial tablet production installations can be subject to variations in ambient temperature, particularly in the summer when temperatures may

*Corresponding author: LGPSD UMR-CNRS-EMAC, Ecole des Mines d'Albi, Campus Jarland, Albi F-81013, France. email: michrafy@enstimac.fr reach $50{ }^{\circ} \mathrm{C}$ in production areas. Such conditions increase the temperature of dies and punches acting on the powder during compaction and hence could affect the mechanical and physical properties of the tablets produced. Examination of certain damaged dies used in pharmaceutical powder compaction reveals scraping on the interior surface in contact with the powder. These scrapes seem to result from melting and hardening of some components of the compacted powders which could be caused by the rise in temperature in the tablet during the compaction process. The two major factors increasing the temperature in the compaction are:

(a) heat generated in the compaction process: heat generated by die wall and particle-particle friction, heat produced by plastic deformation of powders; 
(b) ambient heat (high summer temperatures, heat generation by working machines).

Such heating changes the temperature of tools (dies and punches), increases the difference in temperature between powders and tools, and could favour heat transfer to the powders.

Several studies, using various measurement techniques, have been devoted to the rise in temperature in powder compaction processes $[\mathbf{1}, \mathbf{2}]$. In general, the increase in temperature of a tablet depends on the compressive force, the amount of lubricant, and the speed of compression [1]. However, these studies do not take into account variations in ambient temperature, particularly in the summer where there can be significant rise in the temperature in production areas. The rise in temperature of the tools could contribute to the increase of the temperature in tablets by contact with dies and hence modify the powder behaviour in compaction, in particular, effects on die-wall friction, on the relationship between the pressure transmitted to the lower punch and the pressure applied, or on the ratio of radial stress to applied pressure. These mechanical properties are often used for the study of the powder compression, and knowledge of the variations of these properties with the increase in environmental temperature would help in evaluating the influence of the ambient temperature in production areas on the pharmaceutical powder compaction.

\section{MATERIALS AND METHODS}

Compaction experiments were carried out using a hydraulic press. The upper and lower punches are instrumented by strain gauges measuring the applied and transmitted pressure. A cylindrical die, $21.6 \mathrm{~mm}$ of height and $20 \mathrm{~mm}$ of diameter, is instrumented with a radial strain gauge measuring the contact pressure applied by the powder on the die. In this hydraulic press, the compaction is done

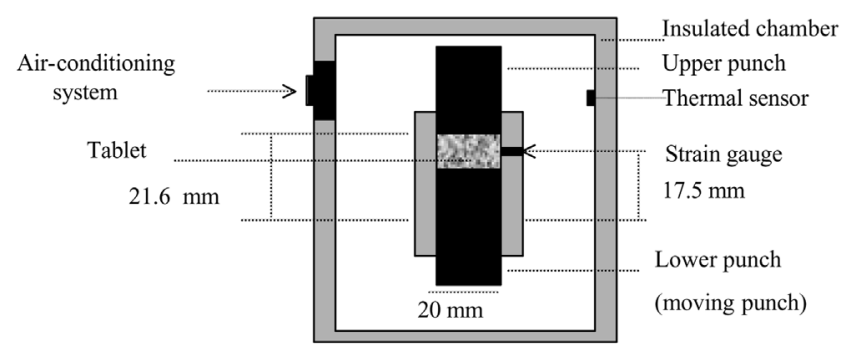

Fig. 1 A Schematic diagram of equipment used to measure the temperature in the chamber the axial stress-strain data, the transmission ratio, and the transfer ratio with the lower punch. The radial strain gauge is positioned at $4.1 \mathrm{~mm}$ from the upper punch (Fig. 1). The die and punch set are placed in a chamber that can be heated by warm air from a controlled temperature unit. The outside of the chamber is heated with a hot water circulating in silver tubes surrounding the chamber and covered with insulating material to ensure a good insulation of the airpunch-die unit. A schematic diagram of the equipment is given in Fig. 1. The temperature inside the chamber is measured with a thermal sensor, also represented in Fig. 1. The compaction tests were carried out with the following chamber temperatures: $20,36,46,53$, and $57^{\circ} \mathrm{C}$. Before each series of tests, the temperature of the chamber was increased up to the desired value. The duration of the heating can take typically $2 \mathrm{~h}$ to reach a temperature of $57^{\circ} \mathrm{C}$.

The powder used in our experiments was a microcrystalline cellulose 'Avicel PH102', which is often used as excipient in pharmacy. The standard properties of this powder are mean particle size $=90 \mu \mathrm{m}$, apparent density $\rho_{\mathrm{r}}=0.27 \mathrm{~g} / \mathrm{cm}^{3}$, and true density $\rho_{\mathrm{t}}=1.60 \mathrm{~g} / \mathrm{cm}^{3}$.

For each temperature of the chamber $(20,36,46$, 53 , and $57{ }^{\circ} \mathrm{C}$ ), a series of three compacts were prepared in $<4 \mathrm{~min}$ at the speed of $11 \mathrm{~mm} / \mathrm{s}$. The mean mass of tablets was $2.5 \mathrm{~g}( \pm 0.01 \mathrm{~g})$. The compaction time of each tablet was $1.4 \mathrm{~s}$. During this time, the thermal sensor does not indicate a notable decrease in temperature. After ejection, the tablets were warm to the touch, but no quantitative measure of the tablet temperature was made. The applied pressure (lower punch) and the pressure transmitted to the upper punch were measured. The radial pressure was also recorded. As the radial pressure is, in general, non-uniform along the height of the tablet, the position of punch was adjusted so that the strain gauge was approximately at the medium height of the tablet (at the end of the compaction). For all the ambient temperatures tested, the temperature of the powder before the filling in the die was $20^{\circ} \mathrm{C}( \pm 0.5)$, the applied pressures were in the range $72-76 \mathrm{MPa}$, and the heights of tablets were in the range $6.11-6.17 \mathrm{~mm}$.

\subsection{Die-wall friction}

In single action powder compaction in a cylindrical rigid die, the stress $\sigma_{\mathrm{u}}$ applied with the moving punch (the lower punch in the used press) is transmitted to the powder and to the die wall with a radial stress $\sigma_{\mathrm{r}}$. The normal stress $\sigma_{\mathrm{b}}$ transmitted to the fixed punch (the upper punch) is less than $\sigma_{\mathrm{u}}$ due to the friction between the powder and the die wall, and between the particles of the powder. To evaluate the friction coefficient, the macromechanical analysis of Janssen-Walker [3] is adopted. In 
this analysis, the particles are treated as continuum and the wall friction coefficient is assumed constant. The resulting transmission ratio $\sigma_{\mathrm{b}} / \sigma_{\mathrm{u}}$ was expressed as $[4]$

$$
\frac{\sigma_{\mathrm{b}}}{\sigma_{\mathrm{u}}}=\exp \left(\frac{-4 \alpha \mu h}{D}\right)
$$

where $\alpha=\sigma_{\mathrm{r}} / \sigma_{\mathrm{u}}$ the transfer ratio and $h / D$ the aspect ratio. In expression (1), $h$ is the current height of the tablet and $D$ its diameter. However, during the compaction, the ratios $\sigma_{\mathrm{b}} / \sigma_{\mathrm{u}}$ and $\alpha$ are recorded at every height of tablet. It is assumed, in this study, that equation (1) is valid for each height $h$ and the resulting die-wall friction coefficient is expressed as

$$
\mu=\ln \frac{\left(\sigma_{\mathrm{b}} / \sigma_{\mathrm{u}}\right)}{(-4 \alpha h / D)}
$$

Equation (2) gives an indirect measurement of the die-wall friction coefficient as a function of the tablet height and hence of the applied pressure. An expression similar to equation (2) was used in reference [5] for the compaction of ductile steel powder and in reference [6] for the compaction of pharmaceutical powder.

In general, $\sigma_{\mathrm{r}}$ and hence $\alpha$ depend on the axial compressive stress and is not uniform over the height of tablet. As the radial gauge is approximately centred on the tablet, the measured value $\sigma_{\mathrm{r}}$ will be considered here to be representative of the mean radial stresses over the height.

A micromechanical approach has been also employed to analyse the die-wall friction [7-9]. The first particulate model was developed in reference [7]; in this, the friction coefficient of particles was assumed to be independent of the applied pressure and hence of the given height of the bed. The stress transmission ratio was expressed as

$$
\frac{\sigma_{\mathrm{b}}}{\sigma_{\mathrm{u}}}=\exp \left(\frac{-4 \alpha \mu H_{0}}{D}\right)
$$

where $H_{0}$ is the initial height of the powder bed.

By examining very small strain compaction of particle assemblies of glass ballotini treated with a boundary lubricant, Adams et al. [8] showed that the transmission ratio depends on the applied pressure and that the friction coefficient of these smooth spherical elastic particles decreases with applied pressure. This latter result was justified by the adhesion model of friction described by Briscoe [9]. In the following, the die-wall friction will be calculated from equation (2) and results will be commented with reference to the micromechanical approach.

\section{RESULTS AND DISCUSSION}

\subsection{Radial stress versus relative density}

Figure 2 shows the radial stress plotted versus the relative density for chamber temperatures of 20 and $57^{\circ} \mathrm{C}$. It can be seen that with the chamber temperature $T=57^{\circ} \mathrm{C}$, the radial pressure is slightly greater than the radial pressure for $T=20^{\circ} \mathrm{C}$ (in the range $0.2-0.6$ of the relative density). This can be explained by the superposition of the pressure of the warm air and the pressure of the solid (powder particles). For the remainder of the compaction, where the two curves are identical, the pressure of the air seems to have a negligible effect probably due to its evacuation in the first stages of the compression.

The jump in the radial stress curve (around 0.38 of the relative density) can be attributed to using two different calibration methods. For low-pressure ranges and relative densities of less than 0.38 , the calibration was made using water. For higher pressure, silicone rubber was used despite of the non-exactly isotropic pressure in the rubber. The water calibration is retained here at low pressure for its isotropy and hence for a good estimation of the radial stress from the applied pressure.

\subsection{Heat transfer analysis}

When the die is at a temperature of $20^{\circ} \mathrm{C}$, the tablet is hotter than the die (temperature of the tablet $=$ temperature of the powder $\left(20^{\circ} \mathrm{C}\right)+$ temperature generated by compaction process). It is followed from that the temperature should decrease in the tablet by thermal transfer towards the die. In contrast, if the temperature of the die is $57^{\circ} \mathrm{C}$, the

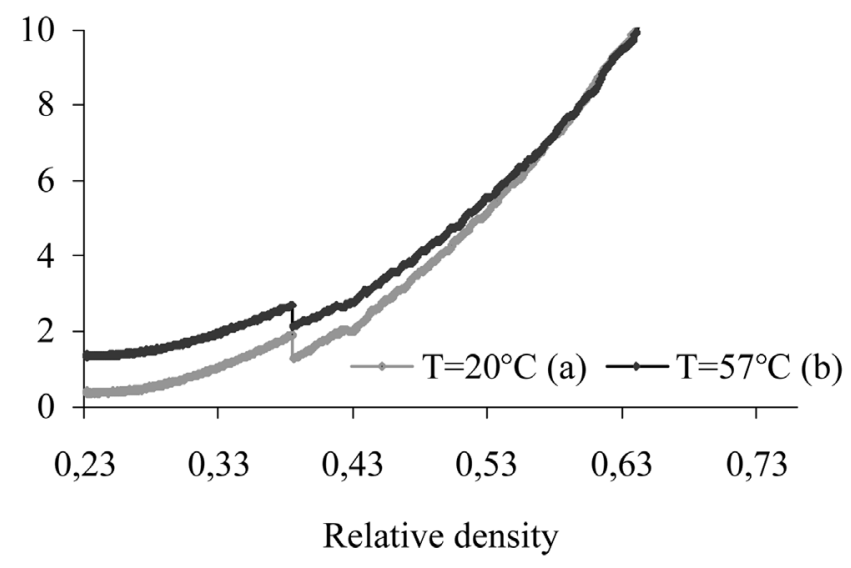

Fig. 2 Radial pressure versus relative density for chamber temperatures $T=20^{\circ} \mathrm{C}$ (a) and $T=57^{\circ} \mathrm{C}$ (b). Compaction of $2.5 \mathrm{~g}$ of MCC (Avicel PH102) with hydraulic press in $21.6 \mathrm{~mm}$ diameter cylindrical die. 
tablet is warmed up by contact with the hot surface of the die. As the radial stress in the case of the room temperature, $T=57^{\circ} \mathrm{C}$, is found to be higher, this suggests that the contact between the hot die wall and the tablet is then better (the contact heat resistance is lower than the case where $T=20^{\circ} \mathrm{C}$ ). It seems reasonable to suppose that the heat transfer from the die to the tablet could be greater. Consequently, a risk of going beyond the melting point of certain powder components is possible. It should be noted that, from physical properties of the compacted powder (effective thermal conductivity and heat capacity) and the contact time between die and punches set and the tablet, the resulting gradient of temperature inside tablet may be analysed by solving the transient heat conduction equation. This work is in preparation.

\subsection{Softening of the compaction behaviour}

The analysis of the curve 'axial strain-axial stress' for the chamber temperatures $T=20$ and $57^{\circ} \mathrm{C}$ shows a slight softening of the compaction behaviour. To appreciate this softening, the difference of axial stresses at $T=20$ and $57{ }^{\circ} \mathrm{C}$ versus the axial strain is plotted in Fig. 3. The stress difference increases up to $5 \mathrm{MPa}$ at the end of the compaction. For the same strain, the stress required to compact the powder is lower for $T=57^{\circ} \mathrm{C}$ than for $20^{\circ} \mathrm{C}$. This softening results from the rise in temperature in the tablet due to the die-wall friction, plastic deformation of the MCC, and the contact with the warm die wall.

\subsection{Die-wall friction and transmission ratio}

Data of the transmission ratio versus the applied pressure is plotted in Fig. 4. For the two temperatures

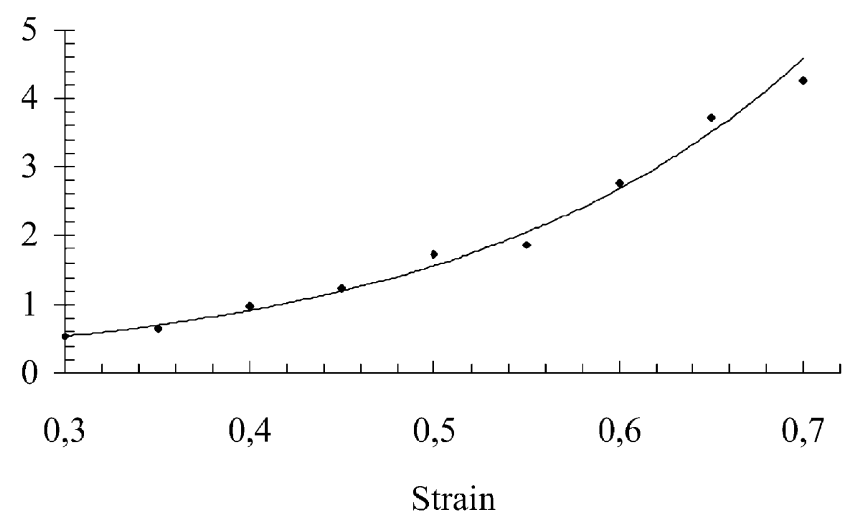

Fig. 3 Difference between axial pressures at $T=20$ and $57^{\circ} \mathrm{C}$ versus axial strain $\Delta \sigma=$ $\sigma_{\mathrm{u}}\left(T=20^{\circ} \mathrm{C}\right)-\sigma_{\mathrm{u}}\left(T=57^{\circ} \mathrm{C}\right)$. Fitted curve: $\Delta \sigma_{20->57}=0.11 \exp (5.37$ strain) with standard deviation $R^{2}=0.99$

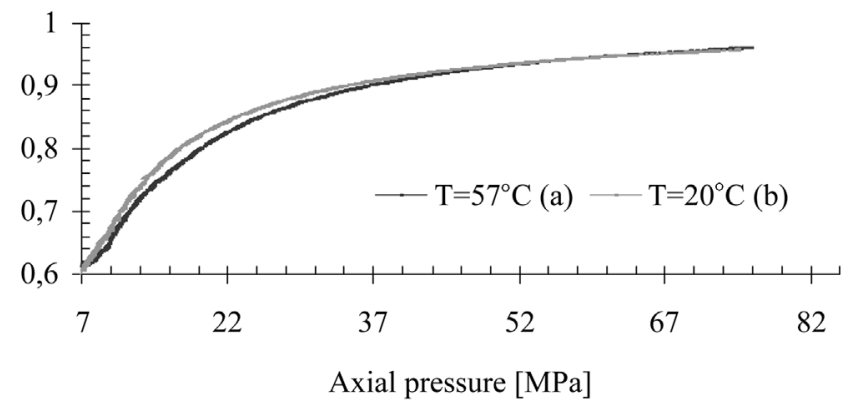

Fig. 4 Transmission ratio $\left(\sigma_{\mathrm{b}} / \sigma_{\mathrm{u}}\right)$ versus applied pressure: (a) transmission ratio at $T=57^{\circ} \mathrm{C}$ and (b) transmission ratio at $T=20^{\circ} \mathrm{C}$

$T=20$ and $57^{\circ} \mathrm{C}$, results show that the transmission ratio increases from 0.6 up to an asymptotic value in the range 7-76 MPa of the pressure. A similar shape of the transmission ratio curve was observed in reference [8] for the compaction of glass ballotini at low pressures. In this latter work, the transmission ratio was modelled by a micromechanical approach that predicts small values at low pressures and increases up to an asymptotic value at large applied stresses.

It is also observed (Fig. 4) that there is a reduction in the transmission load between punches with an increase in the chamber temperature. This is due to the frictional stress at die-wall contact being more higher at $T=57^{\circ} \mathrm{C}$. This behaviour could be taken as a softening in compaction.

The die-wall friction was calculated from equation (2) and results for $T=20$ and $57^{\circ} \mathrm{C}$ were plotted in Fig. 5 versus the applied pressure. In the two cases of chamber temperature, the die-wall friction coefficient decreases with the applied pressure. Its values at $T=$ $57^{\circ} \mathrm{C}$ are greater than those for compaction at $T=20^{\circ} \mathrm{C}$. Globally, it may be concluded that the higher the temperature of the room, the higher the friction coefficient, the radial pressure, and the frictional stress. Consequently, it results in a reduction of the transmission ratio of compaction at $T=57^{\circ} \mathrm{C}$.

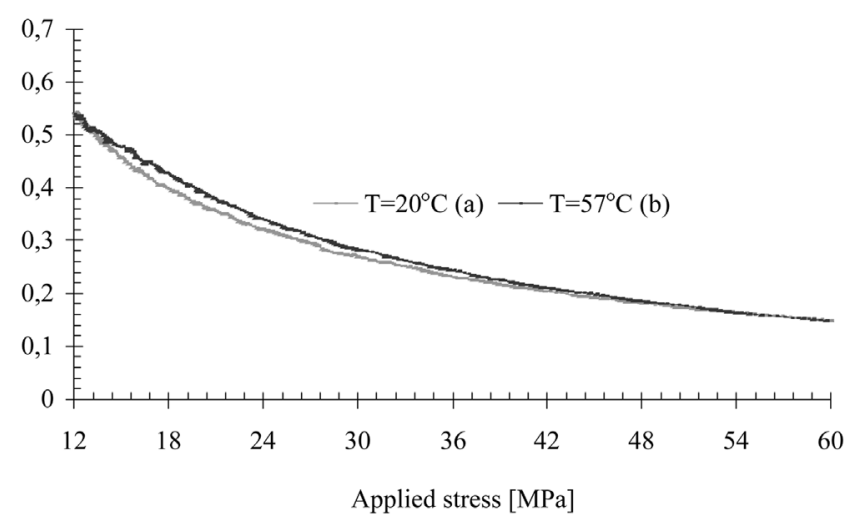

Fig. 5 Die-wall friction versus applied pressure. (a) $T=57^{\circ} \mathrm{C}$ and (b) $T=20^{\circ} \mathrm{C}$ 


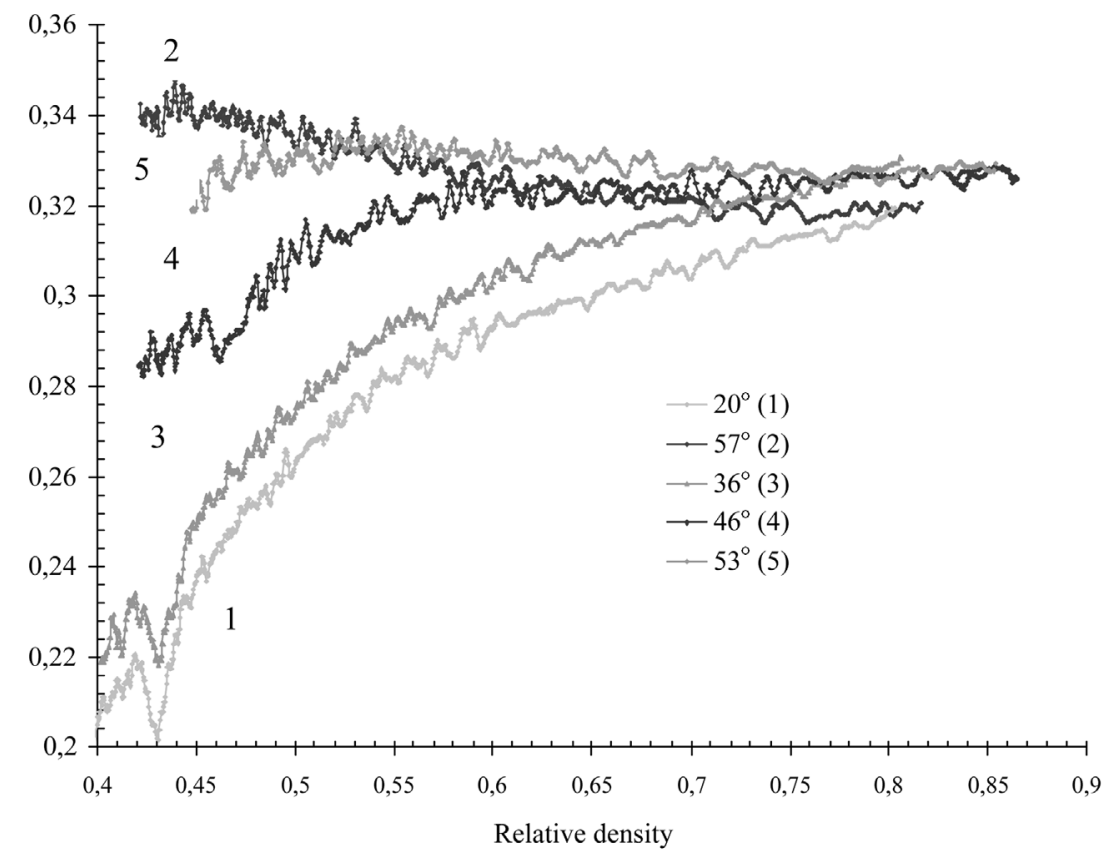

Fig. 6 Transfer ratio versus relative density. Effect of the environmental temperature (1) $T=20^{\circ} \mathrm{C}$, (2) $T=57{ }^{\circ} \mathrm{C}$, (3) $T=36{ }^{\circ} \mathrm{C}$, (4) $T=46{ }^{\circ} \mathrm{C}$, and (5) $T=53^{\circ} \mathrm{C}$

\subsection{Transfer ratio}

The ratio of the radial stress to the axial stress (transfer ratio) is an important parameter in compaction behaviour, because it is often used to calibrate mechanical models of the powder compaction $[\mathbf{1 0}, \mathbf{1 1}]$ or as a die-design factor [12]. Our purpose here is to show changes in the transfer ratio during the compaction when varying the temperature of the chamber, which is considered to be the temperature of the die, the punches, and the surrounding air.

The transfer ratio versus the relative density of the powder for temperatures $T=20,36,46,53$, and $57^{\circ} \mathrm{C}$ is plotted. Figure 6 shows that for temperatures 20 , 36 , and $46^{\circ} \mathrm{C}$, the transfer ratio increases with the relative density and tends towards a constant value, typically 0.32 . However, for the temperatures 53 and $57^{\circ} \mathrm{C}$, the transfer ratio is practically constant in the range $0.4-0.85$ of the relative density. The value found for the transfer ratio 0.32 seems small when compared with values in the literature for the MCC powders (typical values are in the range 0.40.45). It was thought that the transfer ratio depends on the aspect ratio $H / D$, which was typically 0.3 $(H=6.4 \mathrm{~mm}, D=21.6 \mathrm{~mm})$ in our experiments. Compaction of the same powder in a $11.28 \mathrm{~mm}$ diameter cylindrical die at the ambient temperature $\left(T=20^{\circ} \mathrm{C}\right)$ with an aspect ratio equal to 0.22 $(H=2.5 \mathrm{~mm}, D=11.28 \mathrm{~mm})$ gave a transfer ratio of 0.4 which is similar to values given in the literature $[13,14]$.

\section{CONCLUSIONS}

An experimental study has been made on the effects of the environmental temperature of die and punch on the compaction behaviour of a pharmaceutical powder. The analysis was concerned with the mechanical parameters such as the transfer ratio, transmission ratio, and die-wall friction. It was shown that increasing the temperature increases the transfer ratio, the radial pressure, and the die-wall friction. The resulting increase in shear stress between the tablet and the die wall gives a reduction of the transmission load during the compaction. Moreover, a softening behaviour of the compaction is noted with increasing temperature. This softening is probably due to the rising temperature in the powder by compaction and by the heat flux transfer between the die wall and the tablet. It is suggested that these effects analysed in laboratory experiments could be more intense in tablet producing installations subject to variations in ambient temperature.

\section{REFERENCES}

1 Bechard, S. R. and Down, G. B. Infrared imaging of pharmaceutical materials undergoing compaction. Pharm. Res., 1992, 9(4), 521-528. 
2 Ketolainen, J., Ilkka, J., and Paronen, P. Temperature changes during tebletting measured using infrared thermoviewer. Int. J. Pharm., 1993, 92(1-3), 157-166.

3 Neddermann, R. M. Statics and kinematics of granular materials, 1992 (Cambridge University Press, Cambridge).

4 Michrafy, A., Kadiri, M. S., and Dodds, J. A. Wall friction and its effects on the density distribution in the compaction of pharmaceutical excipients. Trans. IChemE, 2003, 81, Part A, 946-952.

5 Cedergren, J., Sorensen, N. J., and Bergmark, A. Threedimensional analysis of compaction of metal powder. Mech. Mater., 2002, 34, 43-59.

6 Sinka, I. C., Cunningham, J. C., and Zavaliangos, A. The effect of wall friction in the compaction of pharmaceutical tablets with curved faces: a validation study of Drucker-Prager cap model. Powder Technol., 2003, 133, 33-43.

7 Isherwood, D. P. Die wall friction effects in the compaction of polymer granules. In Tribology in particulate technology (Eds B. J. Briscoe and M. J. Adams), 1987 (Adam Hilger, Bristol), pp. 234-248.

8 Adams, M. J., McKeown, R., and Whall, A. A micromechanical model for the confined uni-axial compression of an assembly of elastically deforming spherical particles. J. Phys. D: Appl. Phys., 1997, 30, 912-920.

9 Adams, M. J., Briscoe, B. J., and Pope, L. A contact mechanics approach to the prediction of the wall friction of powders. In Tribology in particulate technology (Eds B. J. Briscoe and M. J. Adams), 1987 (Adam Hilger, Bristol), pp. 234-248.

10 Aydin, I., Briscoe, B. J., and Sanlitürk, K. Y. The internal form of compacted ceramic components: a comparison of finite element modelling with experiment. Powder Technol., 1996, 89, 239-254.

11 Michrafy, A., Ringenbacher, D., and Tchoreloff, P. Modelling the compaction behaviour of powders: application to pharmaceutical powders. Powder Technol., 2002, 127, 257-266.

12 Long, W. M. Radial pressures in powder compaction. Powder Metall., 1960, 6, 73-86.

13 Es-Saheb, M. H. Uni-axial strain rate effects in pharmaceutical powders during cold compaction. J. Mater. Sci., 1992, 27, 4151-4159.

14 Kadiri, M. S. Thèse de Doctorat de l'Institut Polytechnique de Toulouse, soutenue le 30 novembre 2004 à l'Ecole des Mines d'Albi-Carmaux. 